\title{
Prophylaxis and treatment of acute lymphoblastic leukemia relapse after allogeneic hematopoietic stem cell transplantation
}

This article was published in the following Dove Press journal:

OncoTargets and Therapy

10 February 2015

Number of times this article has been viewed

\section{Runzhe Chen' \\ Jos L Campbell ${ }^{2,3}$ \\ Baoan Chen'}

'Department of Hematology and Oncology (Key Department of Jiangsu Medicine), Zhongda Hospital, Medical School, Southeast University, Nanjing, People's Republic of China; ${ }^{2}$ Stanford University Department of Radiology, Molecular Imaging Program at Stanford, Palo Alto, CA, USA; ${ }^{3}$ Royal Melbourne Institute of Technology, School of Applied Science, Melbourne, VIC, Australia
Correspondence: Baoan Chen Department of Hematology and Oncology, Zhongda Hospital, Medical School, Southeast University, Dingjiaqiao 87, Gulou District, Nanjing 210009, Jiangsu Province, People's Republic of China

Tel +86258327 2006

Fax +86258327 20II

Email cba8888@hotmail.com
Abstract: Relapse of acute lymphoblastic leukemia remains a major cause of death in patients following allogeneic hematopoietic stem cell transplantation. Several factors may affect the concurrence and outcome of relapse, which include graft-versus-host disease, minimal residual disease or intrinsic factors of the disease, and transplantation characteristics. The mainstay of relapse prevention and treatment is donor leukocyte infusions, targeted therapies, second transplantation, and other novel therapies. In this review, we mainly focus on addressing the impact of graft-versus-host disease on relapse and the prophylaxis and treatment of acute lymphoblastic leukemia relapse following allogeneic hematopoietic stem cell transplantation. We also make recommendations for critical strategies to prevent relapse after transplantation and challenges that must be addressed to ensure success.

Keywords: acute lymphoblastic leukemia, relapse, allogeneic hematopoietic stem cell transplantation, prevention, therapy

\section{Introduction}

Relapse of acute lymphoblastic leukemia (ALL) after allogeneic hematopoietic stem cell transplantation (allo-HSCT) remains a significant therapeutic challenge, especially for adult ALL. ${ }^{1}$ For patients with ALL who relapse after allo-HSCT, the treatment options are limited and the clinical course and prognostic factors affecting outcome have not been well characterized., Although a better understanding of the graft-versus-tumor/graft-versus-leukemia (GVL) effect, ${ }^{4}$ minimal residual disease (MRD), and donor leukocyte infusions (DLIs) ${ }^{5}$ have been achieved in recent decades, predicting ALL relapse after allo-HSCT and finding strategies to overcome ALL relapse remain critical to clinical practitioners. The aim of this article is to review the current concepts regarding risk factors, prevention, and treatment of ALL relapse following allo-HSCT.

\section{Graft-versus-host disease and its impact on relapse}

Numerous reports have demonstrated that graft-versus-host disease (GVHD) is associated with patient relapse after transplantation. ${ }^{6-10}$ In ALL, a potent GVL effect is recognized, ${ }^{1}$ and finding methods to trigger a more potent GVL response without increasing the risk of GVHD is the ultimate goal of HSCT. ${ }^{11}$ However, clinical evidence also suggests that there may be protective GVL effects associated with mild or moderate GVHD. ${ }^{12,13}$ In order to examine whether GVHD is associated with a GVL effect that influences the outcome of allo-HSCT in childhood ALL, Gustafsson Jernberg et al $^{7}$ examined 112 ALL patients and found that 
chronic GVHD independently decreased the risk of relapse (relative risk [RR] 0.44) and further predicted an increased chance of relapse-free survival (RR 1.7) and survival (RR 2.6). The impact of chronic GVHD on survival was most apparent in late-stage ALL. However, acute GVHD was not an independent predictor for relapse or mortality. This study is in support of a GVL effect in childhood leukemia related to chronic GVHD, reducing the risk of relapse and improving survival.

In a recent clinical trial by $\mathrm{Chen}$ et $\mathrm{al}^{14}$ data from 18 patients with ALL who underwent allo-HSCT over the previous 12 years were collated, and they found that high-risk ALL and lack of chronic GVHD were risk factors for relapse (all $P<0.05$ ). Another study, by Lee et $\mathrm{al}^{15}$ focused on adults with ALL who received myeloablative allo-HSCT from a matched sibling or unrelated donor and demonstrated that chronic GVHD, especially the limited type, has a significant antileukemic effect. It was also found that the influence of chronic GVHD on relapse risk was prominent in patients with chromosomal translocations or normal cytogenetics. The positive influence of chronic GVHD on survival rates in ALL patients is also confirmed in several other clinical studies. ${ }^{9,16,17}$ However, the exact mechanisms of this GVL effect are poorly understood at present. Chronic GVHD is an autoimmune syndrome driven by diverse immune processes; thus, the relationship between chronic GVHD and graft-versus-tumor disease needs further analysis and understanding, and may help identify new therapies in the future.

\section{Minimal residual disease and relapse}

Patients with MRD prior to transplantation are more likely to respond positively, and MRD is shown to have a strong correlation with cases of post-transplant relapse. ${ }^{18}$

\section{MRD monitoring before and after transplantation}

Monitoring MRD before and after transplantation would allow doctors to assess a patient's prognosis more effectively and prevent potential relapse. ${ }^{19,20}$ Emerging tools used for monitoring MRD and chimerism could predict patients at highest risk for relapse and provide us with an opportunity to pre-empt and mitigate relapse severity. Patients with increasing chimerism or MRD have been shown to benefit from early withdrawal of immune suppression or donor lymphocyte infusion. ${ }^{21}$ Traditionally, polymerase chain reaction is a way of monitoring for MRD, especially in children. Nowadays, the use of high-throughput sequencing-based MRD monitoring in adults with ALL offers a standardized approach to quantify leukemia MRD in peripheral blood. ${ }^{22}$ Monitoring of MRD by four-color multiparametric flow cytometry could also be a key pre-emptive intervention. ${ }^{23}$

\section{MRD as a prognostic factor for relapse following transplantation}

Several studies have demonstrated that patients at intermediate risk of relapse with low MRD can be considered to have a good prognosis. ${ }^{24-26}$ This was confirmed by Balduzzi et al ${ }^{26}$ in a study in which 82 children and adolescents underwent allo-HSCT for ALL in remission (period 2001-2011, median follow-up 4 to 9 years). Similarly, Terwey et $\mathrm{al}^{25}$ performed a retrospective analysis of serial chimerism assessments in 101 adult HSCT recipients with ALL and of serial MRD assessments in a subgroup of 22 patients, all of whom had received myeloablative conditioning. Patients with higher MRD values after HSCT had the highest incidence of relapse among all the prognostic groups analyzed. In another study by Uzunel et $\mathrm{al}^{27} \mathrm{MRD}$ assessments were performed retrospectively after allo-HSCT in 32 patients with ALL ( 23 children and nine adults). Using immunoglobulin and $\mathrm{T}$-cell receptor rearrangements as clonal markers, MRD was detected after allo-HSCT in nine patients, eight of whom have relapsed. This research has demonstrated that MRD status after induction therapy is one of the most significant prognostic factors. Leung et $\mathrm{al}^{28}$ evaluated 64 children with very-high-risk ALL, and found that higher MRD levels at the time of HSCT predicted poor survival after HSCT $(P=0.0019)$ and that MRD was an independent prognostic factor in multivariate analysis $(P=0.0035)$. A retrospective cohort study by Shah et al of children with acute leukemia or myelodysplastic syndrome who had undergone their first allogeneic transplantation also demonstrated that MRD alone does not adequately predict relapse in all patients, and that MRD positivity was only an independent risk factor predictive of relapse. ${ }^{29}$

\section{Intervening in relapse based on MRD}

Using immune or molecular techniques to establish MRD then using this metric to intervene before relapse occurs has been shown to be feasible. Risk stratification-directed intervention with modified DLIs in patients with standardrisk ALL who are MRD-positive following transplantation could improve transplantation outcomes. ${ }^{30}$

\section{Conflict of the relationship between MRD and ALL}

A recent retrospective cohort analysis of children with acute leukemia after transplantation by Shah et $\mathrm{al}^{31}$ suggested that 
there was no improved survival in those patients whose leukemia was detected in a state of MRD post transplantation. This indicates that the relationship between MRD and ALL relapse might be more complex than we thought, and other significant factors may need to be investigated before drawing conclusions regarding the exclusivity of using MRD alone as a metric for prediction of post-allo-HSCT relapse.

\section{Major risk factors affecting relapse after allo-HSCT}

Given the importance of pre-existing risk factors in predicting post-transplantation ALL relapse, there has been significant effort devoted to elucidating the value of individual and combined factors in patient outcomes (Table 1).

\section{Disease and disease status}

Intrinsic factors of the disease play an important role in ALL relapse. Besides cytogenetics, many patient disease-related and treatment-related factors have been recognized that serve as predictors for outcome, such as age (risk of relapse increases with age), comorbidities, and disparities in human leukocyte antigen (HLA). ${ }^{32,33}$ Factors predicting ALL relapse following allo-HSCT include a high white blood cell level at diagnosis, adverse cytogenetics, a mature B phenotype, and short initial remission. ${ }^{17,34}$ In various clinical trials, sex, age, absence of chronic GVHD for more than 6 weeks from the time of diagnosis to complete remission (CR), active disease at the time of first HSCT along with short time to progression from first HSCT (less than 6 months), and low levels of interleukin-12 post HSCT are also risk factors for relapse after transplantation. ${ }^{17,35-42}$

\section{Gene expression}

Several studies suggest that the expression of particular genes is associated with relapse in patients. In a clinical trial by Gandemer et al, ${ }^{35}$ ETV6/RUNX1 expression were examined in 713 ALL childhood patients and it was found that increased expression was a strong indicator of overall survival post relapse. Another study by Liu et $\mathrm{al}^{43}$ concluded that expression of the mixed lineage leukemia gene in ALL patients may indicate a higher risk of relapse after allo-HSCT. In a study by Krentz et $\mathrm{al}^{24} \mathrm{IKZF1}$ deletion and TP53 mutation were also found to increase the risk after relapse in 204 children treated uniformly for B-cell precursor ALL, and this was confirmed in a clinical trial conducted by Beldjord et al. ${ }^{44}$ Similarly, a high vascular endothelial growth factor-A level, NOTCH1/FBW7 mutations, NOD2/ CARD15 genotypes, activating STAT5B N642H mutation, and CD19 were demonstrated to coincide with relapse after allo-HSCT treatment. ${ }^{45-50}$

\section{Transplant characteristics}

Protection against relapse can be increased using unrelated donors, cord blood donors, or HLA-matched donors. ${ }^{17,37,40,51}$ To improve outcomes and decrease the risk of relapse, younger donors should also be sought..$^{52}$

\section{Prophylaxis against relapse after allo-HSCT}

Patient survival is greatest when relapse does not occur postallo-HSCT, so early detection of relapse and prediction of relapse based on contributing factors is the best approach for overall patient survival. ${ }^{32}$ Based on previous data, we provide

Table I Risk factors of acute lymphoblastic leukemia relapse and associations

\begin{tabular}{ll}
\hline Risk factors & Relapse association \\
\hline Disease and disease status & \\
Age & High relapse with advancing age \\
Sex & High relapse within females \\
Phenotype & High relapse with a mature $B$ phenotype \\
Cytogenetics & High relapse: $t(9 ; 22), t(4 ; \mathrm{II}), \mathrm{t}(\mathrm{I} ; \mathrm{I}), \mathrm{t}(\mathrm{I7} ; \mathrm{I9}), \mathrm{t}(5 ; \mathrm{I}),-7,+8, \mathrm{del}(7 \mathrm{p})$, \\
& complex $(\geq 5$ abnormalities $)$, hypodiploidy, triploidy, MLL translocation \\
MRD & High relapse with detection at various time-specific points \\
Chronic GVHD & High relapse with the absence of chronic GVHD \\
Transplantation & High relapse: short initial remission, $>6$ weeks from the diagnosis to CR, active \\
& disease at the time of first HSCT and short time to progression from first HSCT \\
& Low relapse: young, alternative, unrelated, cord blood donors or HLA-matched \\
donors & High relapse: $\mathrm{MLL}$ expression, IKZFI deletion, TP53 mutation, FBW7 mutation, \\
Gene expression & STAT5B N642H, BCR-ABLI rearrangements, and CDI9 \\
& Low relapse: ETV6/RUNXI expression \\
\hline
\end{tabular}

Abbreviations: CR, complete remission; GVHD, graft-versus-host disease; HLA, human leukocyte antigen; HSCT, hematopoietic stem cell transplantation; MRD, minimal residual disease; MLL, mixed lineage leukemia. 
our recommendations for critical strategies to prevent relapse after transplantation.

\section{Donor lymphocyte infusion}

The GVL effect in ALL is probably one of the most potent strategies with curative potential, and DLI is an attractive option for prophylaxis against relapse of ALL after transplantation. ${ }^{14}$ In a retrospective study by Wang et $\mathrm{al}^{53}$ 88 patients with advanced-stage acute leukemia were treated with prophylactic granulocyte colony stimulating factor-primed peripheral blood stem cells (GPBPCI). The results showed that GPBPCI may increase survival in patients with advanced-stage acute leukemia who receive HLA-mismatched/haploidentical HSCT. A single-center prospective study also demonstrated that patients with ALL who received low-dose prophylactic DLI after conditioning with alemtuzumab were at low risk for relapse; ${ }^{54}$ in addition, it was also shown that DLI should be used as early as possible. ${ }^{14}$ However, the specific mechanism of the role of DLI in relapse still requires further investigation.

\section{Modulation of immunosuppression}

Modulation of immunosuppression may reduce relapse risk and improve ultimate outcome. ${ }^{26}$ Immunomodulatory regimens were also shown to induce moderate GVHD, and to enhance the GVL effect if implemented as soon as possible. ${ }^{14}$

\section{Targeted drugs}

Administration of imatinib early after allo-HSCT could be an effective approach for preventing recurrent $\mathrm{Ph}+\mathrm{ALL}$. ${ }^{55-57}$ Pretransplant imatinib improved both relapse and non-relapse mortality in patients with BCR-ABL-positive ALL according to a recent multicenter clinical trial. ${ }^{58}$ However, the patients experienced some adverse events related to administration of imatinib, such as grade 1-3 nausea, emesis, and serum transaminase elevations. ${ }^{55,56}$ Recently, romidepsin, an anticancer agent undergoing clinical trials, has also been demonstrating utility for patients with relapsed ALL. ${ }^{59}$

\section{Cytokines}

Interleukin-2, a very-well-characterized T-cell growth factor, has also been administered to patients with ALL for relapse prophylaxis. ${ }^{1,60}$ Liu et al $^{61}$ studied 19 patients with ALL who underwent interleukin-2 treatment for a high probability of disease recurrence after allo-HSCT. They found that lowdose interleukin- 2 could be a safe and effective strategy to prevent relapse in ALL patients with a high risk of recurrence after unmodified allo-HSCT. The side effects of this treatment consisted primarily of fever, pain, redness, and swelling at the injection site.

\section{Targeting genes related to relapse}

Some genes are associated with the occurrence of ALL relapse. Targeting these mutated genes with specific treatments may be a possible strategy to prevent relapse. ${ }^{11}$ Several clinical trials have attempted targeting therapy and had good outcomes. For example, Cooke et $\mathrm{al}^{62}$ discovered that targeting the mixed lineage leukemia-AF4 oncogene could inhibit cell proliferation in human ALL, and inhibiting the Wnt pathway also demonstrated a positive outcome in ALL. ${ }^{63,64}$

\section{Strategies and treatment options for relapsed ALL following allo- HSCT}

For relapsed ALL, measures such as DLI, optimized chemotherapy regimens, second transplantation, novel agents, tumor vaccines, and monoclonal antibodies may lead to improvement in survival rates.

\section{Donor lymphocyte infusion}

Among the different therapeutic options, DLIs are probably the most consolidated strategy but their efficacy is quite variable depending on disease state. ${ }^{65-67}$ Very few ALL patients benefit from DLIs because of GVHD. The occurrence of acute GVHD is affected by the degree of HLA matching and the type of donor. The development of chronic GVHD after DLIs is associated with the highest rate of response to DLI and higher survival rates. ${ }^{68}$

Replacing steady-state lymphocytes with peripheral blood grafts (G-PB) and applying a short course of an immunosuppressive agent can reduce the incidence of DLI-associated acute GVHD without affecting relapse or survival of patients with hematological disease after receiving allo-HSCT. ${ }^{11}$ In a study by Zhao et al of 194 patients undergoing allo-HSCT, the patients received mobilized DLI for various clinical reasons and the results showed that infusion with a dose of CD14-positive cells at greater than the 50th percentile was associated with a lower incidence of hematological relapse and longer disease-free survival after mobilized DLI. ${ }^{5}$

However, because of the low likelihood of achieving a durable CR, DLI is not considered standard for patients with relapsed ALL after allo-HSCT. ${ }^{8}$ This has led to further investigation of other forms of adoptive cellular therapies post-allo-HSCT. 


\section{Chemotherapy}

Post-transplantation patients who have relapsed may obtain positive results from chemotherapy. However, the major function of chemotherapy is to decrease tumor load, hence chemotherapy should be combined with other therapeutic treatments for greater effect. A recent study showed that patients with relapsed-refractory ALL treated with fludarabine, cytarabine, and liposomal daunorubicin (FLAD), followed by HSCT, had a better prognosis and less frequent relapse. Thus, FLAD appears to be an effective bridge therapy to HSCT for a subset of acute leukemia patients with a poor prognosis. ${ }^{69}$ Although promising, this treatment regime still needs further investigation to determine its overall effectiveness.

\section{Second transplantation}

The efficacy of second transplantation is mainly affected by disease status, duration from relapse to the first transplantation, previous chemotherapy, and the general condition of the patient. A second transplant is one of the few treatment options that provides the possibility for long-term survival in relapsed ALL patients after allo-HSCT, and there are some successful reports. ${ }^{8,70}$

\section{Targeted therapies}

Imatinib is a targeted drug that can be used to treat $\mathrm{Ph}+$ ALL patients. Several studies have demonstrated that posttransplant administration of imatinib is an ideal treatment for $\mathrm{Ph}+\mathrm{ALL}$ patients, and post-transplant imatinib has also been demonstrated to result in lower relapse rates. ${ }^{71,72}$ However, in a retrospective clinical trial that included $34 \mathrm{Ph}+\mathrm{ALL}$ patients, the researchers discovered that post-transplant administration of imatinib is not an ideal treatment for $\mathrm{Ph}+$ ALL patients whose MRD is positive at allo-HSCT. ${ }^{72}$ Reappearance of BCR-ABL1 transcripts early after HSCT or at higher levels also identifies a small subset of patients who do not benefit sufficiently from imatinib. ${ }^{71}$ Dasatinib, a novel ABL tyrosine kinase inhibitor, was found to have excellent efficacy in Ph+ALL in a recent study ${ }^{73}$ Dasatinib could also eradicate MRD and prevent recurrence, so it has advantages over imatinib, but further studies are needed to confirm its effects.

\section{Tumor vaccines}

A variety of leukemia-associated antigens have been utilized in novel tumor vaccines. Dendritic cells and artificial antigen-presenting cells can be utilized in tumor vaccines to improve the immune response to tumor-associated antigens. ${ }^{74-76}$ Continued advances in tumor immunology and immunotherapy may facilitate the application of these approaches to the treatment of relapsed ALL after allo-HSCT in the future.

\section{Monoclonal antibodies}

Multiple monoclonal antibody-based reagents that target ALL-associated surface antigens have been developed and are under investigation at present..$^{77-80}$ The use of monoclonal antibodies that target tumor-associated antigens would be useful for treating ALL relapse after allo-HSCT, but this still needs further research.

\section{Conclusion}

Despite outstanding advances in our knowledge of ALL in the past three decades, relapsed ALL following an allo-HSCT has a dismal prognosis. Outcomes are particularly poor for patients with relapsed ALL, and overall survival rates are less than $15 \%{ }^{56}$ Better understanding of GVL/GVHD and monitoring MRD before and after transplantation may be helpful for clinicians to determine the best treatment options on a patient-by-patient basis. The prevention and treatment strategies for relapse of ALL after allo-HSCT continue to evolve, with advancing developments using a variety of novel approaches. It is clear that critical information regarding both the progress and prognosis of a patient can be gleaned from every stage of treatment, and when properly interpreted can significantly improve survivability. We are confident that with advances in conditioning regimens, vaccines, graft engineering, and epigenetic modifiers, there is a future ahead with significantly less rate of relapse in ALL after allo-HSCT.

\section{Acknowledgments}

This work was supported by the National Natural Science Foundation of the People's Republic of China (81170492, 81370673), National High Technology Research and Development Program 863 of the People's Republic of China (2012AA022703), National Key Basic Research Program 973 of the People's Republic of China (2010CB732404), Key Medical Projects of Jiangsu Province (BL2014078), Key Discipline of Jiangsu Province (2011-2015), and the Victorian Government of Australia for support in the form of a Victorian postdoctoral research fellowship. The authors thank all the core faculties at the Department of Hematology, Affiliated Zhongda Hospital of Southeast University, for their support and kind review of this manuscript. 


\section{Disclosure}

The authors report that they have no conflicts of interest in this work.

\section{References}

1. Arellano ML, Langston A, Winton E, Flowers CR, Waller EK. Treatment of relapsed acute leukemia after allogeneic transplantation: a single center experience. Biol Blood Marrow Transplant. 2007;13(1):116-123.

2. Weisdorf D. Transplants for leukemia in relapse: when is the best time? Best Pract Res Clin Haematol. 2011;24(4):549-552.

3. Duval M, Klein JP, He W, et al. Hematopoietic stem-cell transplantation for acute leukemia in relapse or primary induction failure. J Clin Oncol. 2010;28(23):3730-3738.

4. Kanate AS, Pasquini MC, Hari PN, Hamadani M. Allogeneic hematopoietic cell transplant for acute myeloid leukemia: current state in 2013 and future directions. World J Stem Cells. 2014;6(2):69-81.

5. Zhao XS, Wang Y, Yan $\mathrm{CH}$, et al. The cell composition of infused donor lymphocyte has different impact in different types of allogeneic hematopoietic stem cell transplantation. Clin Transplant. 2014;28(8): 926-934.

6. Hulegardh E, Hagglund H, Ahlberg L, et al. Outcome after HSCT in Philadelphia chromosome positive acute lymphoblastic leukemia in Sweden: a population-based study. Med Oncol. 2014;31(8):66.

7. Gustafsson Jernberg A, Remberger M, Ringden O, Winiarski J. Graft-versus-leukaemia effect in children: chronic GVHD has a significant impact on relapse and survival. Bone Marrow Transplant. 2003;31(3):175-181.

8. Porter DL, Alyea EP, Antin JH, et al. NCI first international workshop on the biology, prevention, and treatment of relapse after allogeneic hematopoietic stem cell transplantation: report from the committee on treatment of relapse after allogeneic hematopoietic stem cell transplantation. Biol Blood Marrow Transplant. 2010;16(11):1467-1503.

9. Sayehmiri K, Carson KV, Bakhtiyari S, Shokouhi S, Alimoghadam K. Effects of aGVHD and cGVHD according to relapse status on survival rate in patients with acute lymphocytic leukemia. Hematology. 2014;19(8):441-447.

10. Dazzi F, Fozza C. Disease relapse after haematopoietic stem cell transplantation: risk factors and treatment. Best Pract Res Clin Haematol. 2007;20(2):311-327.

11. Lv M, Huang XJ. Allogeneic hematopoietic stem cell transplantation in China: where we are and where to go. J Hematol Oncol. 2012; $5: 10$.

12. Garnett C, Apperley JF, Pavlu J. Treatment and management of graftversus-host disease: improving response and survival. Ther Adv Hematol. 2013;4(6):366-378.

13. Sugita J, Teshima T. [Control of graft-versus-host disease]. Rinsho Ketsueki. 2014;55(2):170-176. Japanese.

14. Chen Y, Xu Y, Fu G, et al. Allogeneic hematopoietic stem cell transplantation for patients with acute leukemia. Chin J Cancer Res. 2013;25(4):389-396.

15. Lee S, Cho B-S, Kim S-Y, et al. Allogeneic stem cell transplantation in first complete remission enhances graft-versus-leukemia effect in adults with acute lymphoblastic leukemia: antileukemic activity of chronic graft-versus-host disease. Biol Blood Marrow Transplant. 2007;13(9):1083-1094.

16. Kumar P, Defor TE, Brunstein C, et al. Allogeneic hematopoietic stem cell transplantation in adult acute lymphocytic leukemia: impact of donor source on survival. Biol Blood Marrow Transplant. 2008;14(12):1394-1400.

17. Pavletic SZ, Kumar S, Mohty M, et al. NCI first international workshop on the biology, prevention, and treatment of relapse after allogeneic hematopoietic stem cell transplantation: report from the committee on the epidemiology and natural history of relapse following allogeneic cell transplantation. Biol Blood Marrow Transplant. 2010;16(7):871-890.
18. Brüggemann M, Raff T, Flohr T, et al. Clinical significance of minimal residual disease quantification in adult patients with standard-risk acute lymphoblastic leukemia. Blood. 2006;107(3):1116-1123.

19. Hourigan CS, McCarthy P, de Lima M. Back to the future! The evolving role of maintenance therapy after hematopoietic stem cell transplantation. Biol Blood Marrow Transplant. 2014;20(2):154-163.

20. Bar M, Wood BL, Radich JP, Doney KC, Woolfrey AE, Delaney C. Impact of minimal residual disease, detected by flow cytometry, on outcome of myeloablative hematopoietic cell transplantation for acute lymphoblastic leukemia. Leuk Res Treatment. 2014;2014:421723.

21. Pulsipher MA, Bader P, Klingebiel T, Cooper LJN. Allogeneic transplantation for pediatric acute lymphoblastic leukemia: the emerging role of peritransplantation minimal residual disease/chimerism monitoring and novel chemotherapeutic, molecular, and immune approaches aimed at preventing relapse. Biol Blood Marrow Transplant. 2009;15 (1 Suppl):62-71.

22. Logan AC, Vashi N, Faham M, et al. Immunoglobulin and T Cell receptor gene high-throughput sequencing quantifies minimal residual disease in acute lymphoblastic leukemia and predicts posttransplantation relapse and survival. Biol Blood Marrow Transplant. 2014;20(9):1307-1313.

23. Bastos-Oreiro M, Perez-Corral A, Martinez-Laperche C, et al. Prognostic impact of minimal residual disease analysis by flow cytometry in patients with acute myeloid leukemia before and after allogeneic hemopoietic stem cell transplantation. Eur J Haematol. 2014;93(3): 239-246.

24. Krentz S, Hof J, Mendioroz A, et al. Prognostic value of genetic alterations in children with first bone marrow relapse of childhood B-cell precursor acute lymphoblastic leukemia. Leukemia. 2013;27(2): 295-304.

25. Terwey TH, Hemmati PG, Nagy M, et al. Comparison of chimerism and minimal residual disease monitoring for relapse prediction after allogeneic stem cell transplantation for adult acute lymphoblastic leukemia. Biol Blood Marrow Transplant. 2014;20(10):1522-1529.

26. Balduzzi A, Di Maio L, Silvestri D, et al. Minimal residual disease before and after transplantation for childhood acute lymphoblastic leukaemia: is there any room for intervention? Br J Haematol. 2014; 164(3):396-408.

27. Uzunel M, Jaksch M, Mattsson J, Ringden O. Minimal residual disease detection after allogeneic stem cell transplantation is correlated to relapse in patients with acute lymphoblastic leukaemia. Br J Haematol. 2003;122(5):788-794.

28. Leung W, Pui CH, Coustan-Smith E, et al. Detectable minimal residual disease before hematopoietic cell transplantation is prognostic but does not preclude cure for children with very-high-risk leukemia. Blood. 2012;120(2):468-472.

29. Shah NN, Borowitz MJ, Steinberg SM, et al. Factors predictive of relapse of acute leukemia in children after allogeneic hematopoietic cell transplantation. Biol Blood Marrow Transplant. 2014;20(7):1033-1039.

30. Yan CH, Liu DH, Liu KY, et al. Risk stratification-directed donor lymphocyte infusion could reduce relapse of standard-risk acute leukemia patients after allogeneic hematopoietic stem cell transplantation. Blood. 2012;119(14):3256-3262.

31. Shah NN, Borowitz MJ, Robey NC, et al. Feasibility of treating post-transplantation minimal residual disease in children with acute leukemia. Biol Blood Marrow Transplant. 2014;20(7):1000-1007.

32. Alyea EP, DeAngelo DJ, Moldrem J, et al. NCI first international workshop on the biology, prevention and treatment of relapse after allogeneic hematopoietic cell transplantation: report from the committee on prevention of relapse following allogeneic cell transplantation for hematologic malignancies. Biol Blood Marrow Transplant. 2010;16(8): 1037-1069.

33. Kako S, Morita S, Sakamaki H, et al. A decision analysis of allogeneic hematopoietic stem cell transplantation in adult patients with Philadelphia chromosome-negative acute lymphoblastic leukemia in first remission who have an HLA-matched sibling donor. Leukemia. 2011;25(2):259-265. 
34. Appelbaum FR, Gooley TA, Ge L, et al. Extramedullary relapse of acute leukemia after allogeneic hematopoietic stem cell transplantation: different characteristics between acute myelogenous leukemia and acute lymphoblastic leukemia. Biol Blood Marrow Transplant. 2014; 20(7):1040-1047.

35. Gandemer V, Chevret S, Petit A, et al. Excellent prognosis of late relapses of ETV6/RUNX1-positive childhood acute lymphoblastic leukemia: lessons from the FRALLE 93 protocol. Haematologica. 2012; 97(11):1743-1750.

36. Stirewalt DL, Guthrie KA, Beppu L, et al. Predictors of relapse and overall survival in Philadelphia chromosome-positive acute lymphoblastic leukemia after transplantation. Biol Blood Marrow Transplant. 2003;9(3):206-212.

37. Nordlander A, Mattsson J, Ringdén O, et al. Graft-versus-host disease is associated with a lower relapse incidence after hematopoietic stem cell transplantation in patients with acute lymphoblastic leukemia. Biol Blood Marrow Transplant. 2004;10(3):195-203.

38. Waller EK, Rosenthal H, Jones TW, et al. Larger numbers of CD4(bright) dendritic cells in donor bone marrow are associated with increased relapse after allogeneic bone marrow transplantation. Blood. 2001;97(10):2948-2956.

39. Poon LM, Hamdi A, Saliba R, et al. Outcomes of adults with acute lymphoblastic leukemia relapsing after allogeneic hematopoietic stem cell transplantation. Biol Blood Marrow Transplant. 2013;19(7): 1059-1064.

40. Matsumoto K, Yamamoto W, Ogusa E, Ishigatsubo Y, Kanamori H. Prognostic index for relapsed acute leukemia after allogeneic stem cell transplant. Leuk Lymphoma. 2014;55(12):2808-2812.

41. Afify Z, Hunt L, Green A, Guttridge M, Cornish J, Oakhill A. Factors affecting the outcome of stem cell transplantation from unrelated donors for childhood acute lymphoblastic leukemia in third remission. Bone Marrow Transplant. 2005;35(11):1041-1047.

42. Reddy V, Winer AG, Eksioglu E, Meier-Kriesche HU, Schold JD, Wingard JR. Interleukin 12 is associated with reduced relapse without increased incidence of graft-versus-host disease after allogeneic hematopoietic stem cell transplantation. Biol Blood Marrow Transplant. 2005;11(12):1014-1021.

43. Liu J, Wang Y, Xu LP, et al. Monitoring mixed lineage leukemia expression may help identify patients with mixed lineage leukemiarearranged acute leukemia who are at high risk of relapse after allogeneic hematopoietic stem cell transplantation. Biol Blood Marrow Transplant. 2014;20(7):929-936.

44. Beldjord K, Chevret S, Asnafi V, et al. Oncogenetics and minimal residual disease are independent outcome predictors in adult patients with acute lymphoblastic leukemia. Blood. 2014;123(24): 3739-3749.

45. Mayor NP, Shaw BE, Hughes DA, et al. Single nucleotide polymorphisms in the NOD2/CARD15 gene are associated with an increased risk of relapse and death for patients with acute leukemia after hematopoietic stem-cell transplantation with unrelated donors. J Clin Oncol. 2007;25(27):4262-4269.

46. Moiseev IS, Lapin SV, Surkova EA, Lerner MY, Vavilov VN, Afanasyev BV. Level of vascular endothelial growth factor predicts both relapse and nonrelapse mortality after allogeneic hematopoietic stem cell transplantation. Biol Blood Marrow Transplant. 2013;19(12): 1677-1682.

47. Agnusdei V, Minuzzo S, Frasson C, et al. Therapeutic antibody targeting of Notch1 in T-acute lymphoblastic leukemia xenografts. Leukemia. 2014;28(2):278-288.

48. Bandapalli OR, Schuessele S, Kunz JB, et al. The activating STAT5B $\mathrm{N} 642 \mathrm{H}$ mutation is a common abnormality in pediatric T-cell acute lymphoblastic leukemia and confers a higher risk of relapse. Haematologica. 2014;99(10):e188-e192.

49. Bonnet M, Loosveld M, Montpellier B, et al. Posttranscriptional deregulation of MYC via PTEN constitutes a major alternative pathway of MYC activation in T-cell acute lymphoblastic leukemia. Blood. 2011;117(24):6650-6659.
50. Topp MS, Gokbuget N, Zugmaier G, et al. Phase II trial of the antiCD19 bispecific $\mathrm{T}$ cell-engager blinatumomab shows hematologic and molecular remissions in patients with relapsed or refractory B-precursor acute lymphoblastic leukemia. J Clin Oncol. 2014;32(36): 4134-4140.

51. Watanabe N, Takahashi Y, Matsumoto K, et al. Prognostic factors for outcomes of pediatric patients with refractory or relapsed acute leukemia undergoing allogeneic progenitor cell transplantation. Biol Blood Marrow Transplant. 2011;17(4):516-523.

52. Godder KT, Hazlett LJ, Abhyankar SH, et al. Partially mismatched related-donor bone marrow transplantation for pediatric patients with acute leukemia: younger donors and absence of peripheral blasts improve outcome. J Clin Oncol. 2000;18(9):1856-1866.

53. Wang Y, Liu DH, Xu LP, et al. Prevention of relapse using granulocyte CSF-primed PBPCs following HLA-mismatched/haploidentical, T-cell-replete hematopoietic SCT in patients with advanced-stage acute leukemia: a retrospective risk-factor analysis. Bone Marrow Transplant. 2012;47(8):1099-1104.

54. Liga M, Triantafyllou E, Tiniakou M, et al. High alloreactivity of lowdose prophylactic donor lymphocyte infusion in patients with acute leukemia undergoing allogeneic hematopoietic cell transplantation with an alemtuzumab-containing conditioning regimen. Biol Blood Marrow Transplant. 2013;19(1):75-81.

55. Carpenter PA, Snyder DS, Flowers ME, et al. Prophylactic administration of imatinib after hematopoietic cell transplantation for high-risk Philadelphia chromosome-positive leukemia. Blood. 2007;109(7): 2791-2793.

56. Tomblyn M, Lazarus HM. Donor lymphocyte infusions: the long and winding road: how should it be traveled? Bone Marrow Transplant. 2008;42(9):569-579.

57. Egan DN, Beppu L, Radich JP, et al. Patients with Philadelphia-positive leukemia with BCR-ABL kinase mutations prior to allogeneic transplantation predominantly relapse with the same mutation. Biol Blood Marrow Transplant. November 10, 2014. [Epub ahead of print].

58. Mizuta S, Matsuo K, Nishiwaki S, et al. Pretransplant administration of imatinib for allo-HSCT in patients with BCR-ABL-positive acute lymphoblastic leukemia. Blood. 2014;123(15):2325-2332.

59. Satwani P, Bavishi S, Saha A, et al. Upregulation of NKG2D ligands in acute lymphoblastic leukemia and non-Hodgkin lymphoma cells by romidepsin and enhanced in vitro and in vivo natural killer cell cytotoxicity. Cytotherapy. May 20, 2014. [Epub ahead of print].

60. Zhang $\mathrm{C}$, Zhang X, Chen XH. Interleukin-2 priming chemotherapy: a strategy to improve the remission of refractory/relapsed $\mathrm{T}$ cell acute lymphoblastic leukemia. Med Hypotheses. 2013;81(5): $878-880$.

61. Liu KY, Chen YH, Liu DH, Xu LP, Huang XJ. A pilot study of lowdose recombinant interleukin-2 for acute lymphoblastic malignancy after unmanipulated allogeneic blood and marrow transplantation. Bone Marrow Transplant. 2008;42(8):535-539.

62. Cooke SL, Marshall J, Martincorena I, et al. MicroRNA-142-3p inhibits cell proliferation in human acute lymphoblastic leukemia by targeting the MLL-AF4 oncogene. Mol Biol Rep. 2013;40(12):6811-6819.

63. Kuhnl A, Gokbuget N, Kaiser M, et al. Overexpression of LEF1 predicts unfavorable outcome in adult patients with B-precursor acute lymphoblastic leukemia. Blood. 2011;118(24):6362-6367.

64. Harrison CJ. Targeting signaling pathways in acute lymphoblastic leukemia: new insights. Hematology Ame Soc Hematol Educ Program. 2013;2013:118-125.

65. Huang XJ. Current status of haploidentical stem cell transplantation for leukemia. J Hematol Oncol. 2008;1:27.

66. Hsu KC, Gooley T, Malkki M, et al. KIR ligands and prediction of relapse after unrelated donor hematopoietic cell transplantation for hematologic malignancy. Biol Blood Marrow Transplant. 2006;12(8): 828-836.

67. van den Brink MRM, Porter DL, Giralt S, et al. Relapse after allogeneic hematopoietic cell therapy. Biol Blood Marrow Transplant. 2010;16 (1 Supp1):S138-S145. 
68. Slesarchuk OA, Babenko EV, Semenova EV, et al. Efficacy of donor lymphocyte infusion in patients after different types of allogeneic hematopoietic stem cell transplantation. Terapevticheskii Arkhiv. 2013;85(7): 26-33.

69. De Astis E, Clavio M, Raiola AM, et al. Liposomal daunorubicin, fludarabine, and cytarabine (FLAD) as bridge therapy to stem cell transplant in relapsed and refractory acute leukemia. Ann Hematol. 2014; 93(12):2011-2018.

70. Tischer J, Engel N, Fritsch S, et al. Second haematopoietic SCT using HLA-haploidentical donors in patients with relapse of acute leukaemia after a first allogeneic transplantation. Bone Marrow Transplant. 2014; 49(7):895-901.

71. Pfeifer H, Wassmann B, Bethge W, et al. Randomized comparison of prophylactic and minimal residual disease-triggered imatinib after allogeneic stem cell transplantation for BCR-ABL1-positive acute lymphoblastic leukemia. Leukemia. 2013;27(6):1254-1262.

72. Nishiwaki S, Miyamura K, Kato C, et al. Impact of post-transplant imatinib administration on Philadelphia chromosome-positive acute lymphoblastic leukaemia. Anticancer Res. 2010;30(6):2415-2418.

73. Watanabe A, Chansu S, Ogawa A, Asami K, Imamura M. Prophylactic post-transplant dasatinib administration in a pediatric patient with Philadelphia chromosome-positive acute lymphoblastic leukemia. Pediatri Int. 2013;55(3):e56-e58

74. Bashey A, Medina B, Corringham S, et al. CTLA4 blockade with ipilimumab to treat relapse of malignancy after allogeneic hematopoietic cell transplantation. Blood. 2009;113(7):1581-1588.
75. Reddy V, Iturraspe JA, Tzolas AC, Meier-Kriesche HU, Schold J, Wingard JR. Low dendritic cell count after allogeneic hematopoietic stem cell transplantation predicts relapse, death, and acute graft-versushost disease. Blood. 2004;103(11):4330-4335.

76. Fukano R, Nishimura M, Ito N, et al. Efficacy of prophylactic additional cranial irradiation and intrathecal chemotherapy for the prevention of CNS relapse after allogeneic hematopoietic SCT for childhood ALL. Pediatr Transplant. 2014;18(5):518-523.

77. Maino E, Sancetta R, Viero P, et al. Current and future management of Ph/BCR-ABL positive ALL. Expert Rev Anticancer Ther. 2014;14(6):723-740.

78. Parameswaran R, Lim M, Fei F, et al. Effector-mediated eradication of precursor B acute lymphoblastic leukemia with a novel Fc-engineered monoclonal antibody targeting the BAFF-R. Mol Cancer Ther. 2014;13(6): 1567-1577.

79. Vedi A, Ziegler DS. Antibody therapy for pediatric leukemia. Front Oncol. 2014;4:82.

80. Piccaluga PP, Martinelli G, Malagola M, et al. Anti-leukemic and anti-GVHD effects of campath-1H in acute lymphoblastic leukemia relapsed after stem-cell transplantation. Leuk Lymphoma. 2004;45(4): $731-733$.
OncoTargets and Therapy

\section{Publish your work in this journal}

OncoTargets and Therapy is an international, peer-reviewed, open access journal focusing on the pathological basis of all cancers, potential targets for therapy and treatment protocols employed to improve the management of cancer patients. The journal also focuses on the impact of management programs and new therapeutic agents and protocols on

\section{Dovepress}

patient perspectives such as quality of life, adherence and satisfaction. The manuscript management system is completely online and includes a very quick and fair peer-review system, which is all easy to use. Visit http://www.dovepress.com/testimonials.php to read real quotes from published authors. 